\title{
V Sección
}

Dossier: Repensar las humanidades: una tarea permanente

\section{Aceleracionismo y arte contemporáneo}

\author{
Adrià Harillo Pla \\ Universidad Complutense de Madrid, España \\ Universidad de Tel Aviv, Israel \\ adria.harillo@gmail.com \\ https://orcid.org/0000-0002-4005-9643
}

Recibido: 28 de marzo de 2018

Aceptado: 30 de abril de 2018

\section{Resumen:}

En el presente artículo se presenta el concepto de Aceleracionismo, aunque no se realizará un análisis profundo del término. La principal aportación de este texto pretende ser, por el contrario, la aplicación del movimiento aceleracionista al caso del arte contemporáneo. Si bien este intento de unión ya aporta un valor académico por sí mismo, la hipótesis concreta sobre la que se trabaja y que será aquí desarrollada es que, debido a las particularidades institucionales del arte contemporáneo, el Aceleracionismo no es un mecanismo válido para su superación y cambio de paradigma, si es que un cambio de esta naturaleza fuese necesaria.

Palabras clave: Teoría institucional; arte contemporáneo; aceleracionismo; sociología del arte; filosofía del arte; mercado del arte.

\section{Accelerationism and contemporary art}

\section{Abstract:}

In the present article, the concept of Accelerationism is presented, although an indepth analysis of the term will not be made. The main contribution of this text intends to be, on the contrary, the application of the accelerationist movement to the case of contemporary art. Although this attempt at union already provides an academic value in itself, the concrete hypothesis on which we work and which will

\section{(C) $(\Theta \odot$}

La Revista Estudios es editada por la Universidad de Costa Rica y se distribuye bajo una Licencia Creative Commons Atribución-NoComercial-CompartirIgual 3.0 Costa Rica. Para más información envíe un mensaje a 
Revista Estudios, (36), 2018.

ISSN 1659-3316

Junio 2018-Noviembre 2018

Harillo Pla Adrià

be developed here is that, due to the institutional particularities of contemporary art, Accelerationism is not a valid mechanism for its overcoming and change of paradigm, if a change of this nature was necessary.

Keywords: Institutional theory; contemporary art; accelerationism; sociology of art; philosophy of art; art market.

Como es de obligación en toda obra académica que se precie, se haría imposible el comenzar este artículo sin la correspondiente contextualización de los contenidos que serán en él vertidos. Semejante procedimiento debe auxiliar al lector a comprender tanto la situación en la que el texto ha sido realizado como los contenidos en él expuestos y su razón de ser. Esta actividad, sin ningún género de duda, tiene un valor esencial en los argumentos aquí presentados que, al fin y al cabo, es lo de suma importancia cuando de asuntos del conocimiento se trata.

En este sentido y dirección ha de precisarse que, el artículo, es el resultado de la comunicación realizada a fecha 26 de febrero de 2018 en el II Congreso Universitario: Estudios Humanísticos, Arte y Cultura organizado por la Universidad de Costa Rica. No es menos cierto, empero, que existe aquí la pretensión de proporcionar al lector de una forma más dilatada lo que, por cuestiones de tiempo y logística, allí tuvo que ser más sucinto. Además, este ensayo publicado supone un instrumento ideal para poder dar alcance a aquellos que, por razones de diversa índole, no pudieron asistir al congreso y presenciar las comunicaciones en las fechas a ello destinadas. Cabe agregar, a su vez, el previo agradecimiento a la posibilidad de participar en tal acontecimiento a la Universidad de Costa Rica, a la Escuela de Estudios Generales de la ya referida universidad y a Gerard Vilar i Roca, quien fue profesor del autor de este texto en la Universidad Autónoma de Barcelona. De hecho, esta reflexión teórica nace de su invitación a la participación en uno de los seminarios del doctorado en Filosofía de tal universidad. Sin los

\section{(C) $(00$}

La Revista Estudios es editada por la Universidad de Costa Rica y se distribuye bajo una Licencia Creative Commons Atribución-NoComercial-CompartirIgual 3.0 Costa Rica. Para más información envíe un mensaje a 
conocimientos y amabilidad como convidante, una vez más, del Doctor Vilar, la elaboración de este escrito no habría sido posible.

En base a estas mencionadas consideraciones, el título del texto es, como no podría ser de otro modo, el de aquella comunicación: "Aceleracionismo y arte contemporáneo". No obstante, de forma muy legítima el lector podría preguntarse, ¿qué es el Aceleracionismo? Haciendo una analogía con los principios inductivos que la lógica defiende, debemos ir de lo más pequeño -lo particular- a lo más grande -lo general, el título completo- para poder obtener un resultado lo más satisfactorio posible. Para ello, es este el primer vocablo a ser analizado.

En lo que al Aceleracionismo se refiere, esta es principalmente una propuesta de índole política más que artística. En otras palabras: su vinculación al arte es, posiblemente, la contribución de mayor valor de este ensayo pues, el embrión del Aceleracionismo como tal, es un movimiento que puede ya hallarse en los pasados textos de teoría marxista. Sin ir más lejos, fue el propio Karl Marx -con el apoyo de su compañero Engels en la publicación- quien, en su obra primordial titulada "El Capital", aportó la base teórica para que, con el transcurrir del tiempo, el Aceleracionismo se instaurase en sentido estricto. (Marx, 2000) A pesar de esto, para comprender el Aceleracionismo es preciso informar, previamente, de que para Marx la lógica del sistema capitalista no era factible, entre otras razones, por la tipología de relaciones de producción que conllevaba. Dadas las condiciones que anteceden, el autor de Tréveris elaboró, con el objetivo de ilustrar tales errores lógicos -contradicciones del sistema-, la analogía con un corsé. Así, debería advertirse que, según las conjeturas del afamado pensador, la lógica del sistema capitalista se hallaba encorsetada $y$, sus dinámicas inherentes, terminarían por desencajar y destruir este corsé ideológico en el cual las relaciones productivas se encontraban comprimidas. Este desajuste debía conceder la posibilidad de dar lugar a lo que él y Engels vaticinaron: el socialismo $y$, en el más ilusorio de los casos en base a las tentativas malogradas, el comunismo.

\section{(c) (i) (9) (2)}

La Revista Estudios es editada por la Universidad de Costa Rica y se distribuye bajo una Licencia Creative Commons Atribución-NoComercial-CompartirIgual 3.0 Costa Rica. Para más información envíe un mensaje a 
El Aceleracionismo es, cabe agregar, una postura teórica que no parte de la pretensión de omitir activa o pasivamente las prácticas capitalistas, sino que propone multiplicar su utilización hasta el extremo de lo posible. Los defensores de semejante posicionamiento creen que, de este modo, las propias contradicciones internas del sistema en lo que a sus relaciones productivas se refiere derivarían, a modo de consecuencia, en la destrucción de tal corsé y del tan denostado sistema por parte de Marx. Aunque el Aceleracionismo como teoría siempre ha existido de un modo más o menos significativo, en las actuales fechas ha experimentado un significativo repunte de manos de autores como Armen Avanessian o Nick Land. (Mackay \& Avanessian, 2014) Hecha esta observación cabe agregar que, como el lector ya habrá sido capaz de percibir, el nombre del movimiento deriva, precisamente, de la actividad propuesta: acelerar el capitalismo -hasta que se destruya por sí mismo-.

Con el objetivo de proseguir con nuestra aproximación a este tema y dejando de lado la parte más política del movimiento -algo en lo que el autor de este escrito no es experto y que, en consecuencia, cualquier docto en la materia realizaría de forma mucho más convincente-, debemos prestar atención al segundo de los factores que conforman el título de este artículo, a saber: el arte contemporáneo. ${ }^{1}$

$\mathrm{Si}$ bien es cierto que más allá de las inclinaciones personales parece considerablemente ajustado a la realidad el defender que no se dispone de una definición clara, concisa y compartida acerca de lo que es el arte, sí parece lo suficientemente aceptada la consideración de que, el arte, es aquello que se encuentra así determinado por una institución artística. ${ }^{2}$ A pesar de que -como con frecuencia ocurre en casi todas las disciplinas no exactas- el enfoque de cada uno de los distintos autores a igual cuestión resulta en teorías significativamente dispares, la idea de una institución con sus agentes, motivaciones y mecanismos parece comúnmente aceptada. $^{3}$

Es en este orden de ideas, como consecuencia del paso de la aisthesis a la askesis y sumado a la ya mencionada indefinición del arte, la institución adquiere 
el completo mando sobre el arte. (Bourdieu, 1999, p. 64) Una afirmación de semejante naturaleza como la aquí realizada reside en que, sin una definición clara, no existe un valor normativo falsable sobre aquello que está bien y aquello que no, sobre unas condiciones de necesidad o de posibilidad y, menos aún, sobre los criterios categorizadores. Esto impide, a su vez, el pensar en un paradigma artístico en términos cualitativos, imposibilitando, por ende, el reflexionar sobre futuras modificaciones paradigmáticas en sentido de evolución o progreso -vocablos que implican ya una transformación positiva-. ${ }^{4}$ De todo esto se desprende que, sin una idea clara en términos de objetividad sobre lo que es el arte y sin una meta preestablecida, tal actividad aceleracionista es ineficaz en tanto que no se puede destruir algo que no se encuentra normalizado. ${ }^{5}$

En el caso del arte en general y del contemporáneo en particular hay otro elemento de vital importancia que, a entender del autor del presente artículo, paraliza cualquier posible triunfo del Aceleracionismo como herramienta para el comienzo de un nuevo paradigma artístico, y es la naturaleza de las propias instituciones del arte. Toda institución, se destine ésta a lo que se destine, puede ofrecer dos tipos de contestaciones ante las situaciones externas: respuestas rígidas o respuestas flexibles. ${ }^{6}$ En el caso del arte, que es al fin y al cabo el ente de nuestro análisis, la gran mayoría de instituciones que han sobrevivido con el paso del tiempo y que, en la actualidad, atesoran gran renombre y poder decisor en lo que al arte se refiere son aquellas que han reaccionado a los momentos de crisis del paradigma haciendo uso de respuestas de tipo flexible. ${ }^{7}$ El caso del grafiti, de las Vanguardias y un largo etcétera que no detallaremos aquí en profundidad para no convertir este ensayo en una lectura de Historia del arte son algunos de los casos axiomáticos de semejante afirmación. En contraposición a éstas, aquellas que han venido suministrado réplicas más firmes a lo largo de su existencia han terminado por desaparecer, por ver enormemente reducida su importancia en el interior del sistema artístico o, en algunos casos -los menos-,

\section{(C) $(00$}

La Revista Estudios es editada por la Universidad de Costa Rica y se distribuye bajo una Licencia Creative Commons Atribución-NoComercial-CompartirIgual 3.0 Costa Rica. Para más información envíe un mensaje a 
sobreviven en la actualidad aunque sin que quede del todo claro cuál es su función.

En otro orden de ideas pero en directa ligazón con lo aquí expresado, e independientemente del tipo de datos utilizados -ya sean históricos, psicológicos, económicos, etcétera- nada hace presagiar que en el medio e incluso en el largo plazo el arte deje de ser un objeto de deseo. De aceptarse tal consideración y como consecuencia de las ya citadas respuestas flexibles mediante las cuales las instituciones artísticas amplían el paradigma de arte, nada hace pensar que el corsé al que Marx hacía referencia vaya a quebrarse. Si se aplica esa representación del corsé también al paradigma del arte -en tanto que el arte no deja de ser un objeto insertado en un sistema de producción capitalista- parece que, una actitud aceleracionista, lo único que comportaría es ensanchar semejante corsé, pero bajo ningún concepto romperlo. Podría decirse, además, que ante una ampliación de este tipo se deduciría lo antagónico a los efectos previstos y deseados, insertando las nuevas formas y productos artísticos en el mismo sistema y resultando de ello una coyuntura no deseada por los defensores del movimiento. Podría ser pensado, no obstante, que si en algún momento determinado una mayoría representativa de los individuos que constituyen los agentes de este corsé decidiesen que el arte actualmente aceptado según los paradigmas no es válido, las prácticas actuales quedarían fuera de lo que se cataloga como arte. Esta sería una posible respuesta a lo intrincado de esta situación. Sin embargo, debido a la lógica de funcionamiento del propio Mundo del arte, esto no sería viable ya que quienes se expresan y quienes permiten a las instituciones sobrevivir no son la suma individual de cada uno de los miembros, sino de aquellos con grandes recursos dinerarios. (Harillo, 2015)

Aceptando esta premisa podría incluso postularse que, los miembros que reúnen estas características, podrían expresar exactamente el mismo posicionamiento dinero mediante. Tal como se ha venido defendiendo con anterioridad, empero, semejante procedimiento daría lugar a nuevas formas de creación o a formas ya 
conocidas -aunque bajo el influjo de determinadas disimilitudes tal como la Historia ya se ha ocupado de mostrar en movimientos como el Neorromanticismo y otros tantos neos-. En este sentido y haciendo uso de los razonamientos precedentemente introducidos, incluso en el caso de que este proceder aconteciese, ello restaría incluido en el interior del mismo sistema institucional y capitalista, que pasaría a contener también estas prácticas siguiendo, por ende, formando parte del mismo corsé a pesar de los cambios que pudiesen producirse en algunos aspectos poco esenciales y que, en consecuencia, deberían ser catalogados de accidentales o no esenciales. Para concluir el presente análisis teórico, hay dos aspectos que deben ser destacados. El primero de ellos, y desde una perspectiva descriptiva de los hechos aquí presentados es que, la indefinición del arte y los propios mecanismos que operan en el interior de esta suerte de sistema institucional del arte hacen, por todo lo anterior descrito, que el Aceleracionismo no sea una herramienta viable para la ruptura de este corsé o, por lo menos, no en el caso del arte contemporáneo y actual. El segundo de los aspectos, éste proporcionado desde un enfoque que irradia eminentemente una sugerencia, es el de proponer que, probablemente, lo único que podría permitir romper este corsé paradigmático sería el hallazgo de una definición falsable del vocablo "arte". La sugerencia presentada en este segundo punto conclusivo significaría, no obstante, convertir el arte en algo mucho más científico de lo que a día de hoy es. Sin embargo, el autor es muy consciente de que, con un gran número de posibilidades, para muchos esto sería un error. El autor de este artículo, empero, no se posiciona al respecto y se abstiene de cualquier forma de batalla argumentativa con quienes prefieren sostener este punto de vista pues no es la intención de este texto ni lo ha sido nunca el desarrollar un juicio de valor. En otras palabras: la conclusión de este artículo es que el Aceleracionismo no aplica al arte contemporáneo de forma exitosa debido a las particularidades del sistema institucional artístico y que, esto, será así hasta que no se proporcione una definición científica del arte, aun sabiendo que esta propuesta estará sujeta a

\section{(c) (i) (2)}

La Revista Estudios es editada por la Universidad de Costa Rica y se distribuye bajo una Licencia Creative Commons Atribución-NoComercial-CompartirIgual 3.0 Costa Rica. Para más información envíe un mensaje a 
Revista Estudios, (36), 2018.

ISSN 1659-3316

Junio 2018-Noviembre 2018

Harillo Pla Adrià

críticas, unas críticas que no serán aquí detalladas por no ser esta la finalidad de lo aquí presentado.

\section{Notas}

1. Ello no significa que algunos de los autores que han explorado el Aceleracionismo no se hayan también adentrado en el campo de la Estética. El propio Armen Avanessian es uno de los casos que así lo ha hecho, como puede observarse en la sección de bibliografía de este mismo trabajo.

2. De entre los principales autores que han desarrollado esta perspectiva cabe destacar a Danto y a Dickie desde la Filosofía o a Becker desde la Sociología.

3. Esta afirmación podría dotarse de carácter de axioma pues lo expuesto actúa casi como una suerte de ley científica, si bien algunos autores establecen una pequeña variación en estos elementos y consideran que lo importante son: composición, entorno, estructura y mecanismo.

4. Esto es lo que se desprende de la definición plasmada en la última edición del Diccionario de la Real Academia.

5. Muchos son los autores que han seguido esta línea teórica. De forma contemporánea y sucinta, la producción académica de Ovejero es de alto interés.

6. La terminología de "respuesta flexible" y "respuesta rígida" corresponde a Simmel. Debe precisarse, a su vez, que desde el lenguaje común, la institución suele hacer referencia a una estructura de tipo burocrático encargada de la realización de tareas que suscitan un interés público o común como, por ejemplo, las instituciones sanitarias tienen cura de la salud, las militares de la defensa de un territorio o, las instituciones educativas, de la educación. Desde el campo de la Sociología, la institución es un modelo de comportamiento con valor normativo en una sociedad.

7. La referencia al paradigma y sus transformaciones se hace teniendo en consideración la teoría de Kuhn.

\section{(c) (i) (2)}

La Revista Estudios es editada por la Universidad de Costa Rica y se distribuye bajo una Licencia Creative Commons Atribución-NoComercial-CompartirIgual 3.0 Costa Rica. Para más información envíe un mensaje a revistaestudios.eeg@ucr.ac.cr. 
Revista Estudios, (36), 2018.

Junio 2018-Noviembre 2018

ISSN 1659-3316

Harillo Pla Adrià

\section{Bibliografía}

Avanessian, A. et al. (2011). Aesthetics and contemporary art. Berlin: Sternberg Press.

Bourdieu, P. (1988). La Distinción: criterios y bases sociales del gusto. Madrid: Taurus.

Harillo, A. (2015). El mercado del arte. Una ruptura. La Albolafia: Revista de Humanidades y Cultura, 4, 155-166. Recuperado de https://dialnet.unirioja.es/servlet/articulo?codigo $=5139108$

Harillo, A. (2018). El sentit de les Facultats de Belles Arts. Manuscrito en preparación

Kuhn, T. (2006). La estructura de las revoluciones científicas. México DF: FCE Fondo de Cultura Económica.

Llacay, T. (2005). Nuevo arterama: historia del arte. Barcelona: Vicens Vives.

Lucas, F. (2014). El compromiso del creador: ética de la estética. Barcelona: Galaxia Gutenberg Círculo de Lectores.

Mackay, R. \& Avanessian, A. (2014). Accelerate. Falmouth: Urbanomic Media Ltd.

Marx, K. (2000). El capital: crítica de la economía política. Tres Cantos, Madrid: Akal Ediciones.

Real Academia. (2014). Diccionario de la lengua española. Madrid: Real Academia Española.

Tjaden, K. H. (1983). ¿Qué significa que "las fuerzas productivas harán estallar las relaciones de producción capitalista?. Mientras tanto, 16, 133-144. Recuperado de https://dialnet.unirioja.es/servlet/articulo?codigo $=3383254$

Vidal-Folch, I. (2008, abril 7). "Las frases de Heidegger son las propias de un esquizofrénico". El País. Recuperado de https://elpais.com/diario/2008/04/04/cultura/1207260003_850215.html

\section{(c) (i) (2)}

La Revista Estudios es editada por la Universidad de Costa Rica y se distribuye bajo una Licencia Creative Commons Atribución-NoComercial-CompartirIgual 3.0 Costa Rica. Para más información envíe un mensaje a revistaestudios.eeg@ucr.ac.cr. 